\title{
Correction to: Estimation of exposure durations for vitamin D production and sunburn risk in Switzerland
}

\author{
A. Religi ${ }^{1} \cdot$ C. Backes ${ }^{2,3} \cdot$ A. Chatelan ${ }^{2} \cdot$ J.-L. Bulliard ${ }^{2} \cdot$ L. Vuilleumier ${ }^{4} \cdot$ L. Moccozet $^{1} \cdot$ M. Bochud $^{2} \cdot$ D. Vernez $^{3}$
}

Published online: 7 May 2019

(c) Springer Nature America, Inc. 2019

Correction to: Journal of Exposure Science and Environmental Epidemiology

https://doi.org/10.1038/s41370-019-0137-2

published online 16 April 2019

In the original article, the authorship list was given as

“A. Religi ${ }^{1}$, C. Backes ${ }^{2,3}$, A. Chatelan ${ }^{2}$, J.-L. Bulliard ${ }^{2}$,
L. Vuilleumier ${ }^{4}$, L. Moccozet ${ }^{1}$, M. Bochud ${ }^{2}$, D. Vernez ${ }^{3}$." This has been updated to "A. Religi"1, C. Backes" ${ }^{* 2,3}$, A. Chatelan $^{2}$, J.-L. Bulliard ${ }^{2}$, L. Vuilleumier ${ }^{4}$, L. Moccozet ${ }^{1}$, M. Bochud ${ }^{2}$, D. Vernez ${ }^{3}$ ".

*Co-first authors.

\footnotetext{
A. Religi

arianna.religi@unige.ch

1 Centre Universitaire d'Informatique (CUI), University of Geneva, Geneva, Switzerland

2 Institute of Social and Preventive Medicine (IUMSP), Lausanne University Hospital (CHUV), 1010 Lausanne, Switzerland

3 Institute for Work and Health, University of Lausanne and Geneva, 1010 Epalignes- Lausanne, Lausanne, Switzerland

4 Federal Office of Meteorology and Climatology (MeteoSwiss), Payerne, Switzerland
} 